E R R A TA

\title{
Erratum: A crowdsourcing evaluation of the NIH chemical probes
}

Tudor I Oprea, Cristian G Bologa, Scott Boyer, Ramona F Curpan, Robert C Glen, Andrew L Hopkins, Christopher A Lipinski, Garland R Marshall, Yvonne C Martin, Liliana Ostopovici-Halip, Gilbert Rishton, Oleg Ursu, Roy J Vaz, Chris Waller, Herbert Waldmann \& Larry A Sklar

Nat. Chem. Biol. 5, 441-447 (2009); published online 17 June 2009; corrected after print 17 June 2009

In the version of this article initially published, the phrase "Though MLI and its pilot phase budget and superficially modest productivity were subject to industrial criticism” originally cited reference 3, but should cite reference 2. The error has been corrected in the HTML and PDF versions of the article. 